\title{
La propuesta de Alejo Carpentier en "Lo real maravilloso de América" (1948) y la mirada surrealista insular en Isla cofre mítico (1951) de Eugenio F. Granell'
}

\author{
Carmen Cañete Quesada ${ }^{2}$ \\ Florida Atlantic University (Estados Unidos) \\ ORCID: 0000-0003-1692-0023
}

Recibido: 15 de marzo de 2019

Aceptado: 10 de mayo de 2019

\begin{abstract}
"Viviendo en Santo Domingo sentí casi físicamente la idealización extraordinaria que la poesía hizo acerca del fenómeno geográfico de las islas, elevándolas con frecuencia al plano de lo maravilloso".
\end{abstract}

Eugenio F. Granell, 2000: 61.

\section{RESUMEN}

El presente estudio ofrece puntos de comparación y contraste entre la mirada insular caribeña del artista y autor exiliado Eugenio F. Granell y la tesis identitaria sobre América Latina del escritor y musicólogo Alejo Carpentier. En su ensayo "Lo real maravilloso de América", Carpentier denunciaba la falsa representación de América Latina por parte de los seguidores de la corriente surrealista que -como André Breton y Granell en su libro Isla cofre mítico- fueron arrastrados al nuevo continente por las guerras en Europa. El interrogante de quién podría adjudicarse el legítimo papel de representante de América, nos hace cuestionar si realmente Carpentier, de origen europeo y formado intelectualmente en París, logró plasmar la autenticidad americana a la que aspiraba en su ensayo. Partiendo de esta duda, el presente estudio girará en torno a las siguientes preguntas: ¿en qué diferían el acercamiento insular de Granell y los argumentos de los que se sirvió Carpentier para representar el paisaje de América Latina? ¿A qué modelos recurrieron ambos escritores y qué problemas presentaban estas dos representaciones del escenario americano? Y, finalmente, ¿se podría interpretar Isla cofre mítico como una respuesta o reacción a las críticas hacia la corriente surrealista que aparecen en el ensayo de Carpentier?

Palabras clave: Eugenio F. Granell, Alejo Carpentier, identidad insular, lo real maravilloso, exilio español

\footnotetext{
${ }^{1}$ Alejo Carpentier's Proposal in "The Real Marvelous in America" (1948) and the Insular Surrealist Approach in Eugenio F. Granell's Island Mythical Coffer (1951)

${ }^{2}$ Ph.D. en Literatura Hispánica, Vanderbilt University. Profesora Asociada de Español en Harriet L. Wilkes Honors College, Florida Atlantic University. Correo electrónico: ccaneteq@fau.edu
} 


\section{ABSTRACT}

This study offers comparative and contrastive arguments between exiled artist and author Eugenio F. Granell's Caribbean insular view, and the identity thesis of Latin America provided by writer and musician Alejo Carpentier. In his essay "Lo real maravilloso de América" ["The Real Marvelous in America"], Carpentier denounced the false representation of Latin America on the part of the followers of the Surrealist movement that -like André Breton and Granell in his book Isla cofre mitico [Island Mythical Coffer]- were dragged to the New Continent by the wars of Europe. Amidst a lack of consensus regarding who could legitimately represent America through their work, it has been called into question whether Carpentier, of European origin and formed intellectually in Paris, was able to capture the authenticity of America, as he aspired to in his essay. Departing from this problem, this study will revolve around the following questions: In what ways does Granell's insular approach differ from Carpentier's arguments that he employed to support his depiction of Latin American reality? What sources did both writers use, and what problems did these two representations of the American scenery present? And finally, can Isla cofre mítico be interpreted as a response or reaction to the criticism with respect to the surrealist currency that appeared in Carpentier's essay?

Key words: Eugenio F. Granell, Alejo Carpentier, insular identity, the real marvelous, Spanish exile

\section{INTRODUCCIÓN}

El presente estudio ofrece puntos de comparación y contraste entre la mirada insular antillana del artista, músico y escritor español Eugenio F. Granell (1912-2001), y la tesis identitaria sobre América Latina del escritor, musicólogo y diplomático establecido en Cuba, Alejo Carpentier (1904-1980). Mi propósito es contrastar la visión europea de un español conocedor del trópico, Granell, con la interpretación americana de un suizo-caribeño conocedor de Europa, Carpentier. Nos encontramos ante dos miradas muy distintas, con enfoques y propósitos de variada naturaleza. Granell vivió en el exilio en República Dominicana (1940-1946) y Puerto Rico (1950-1957) con motivo de la Guerra Civil Española (1936-1939) y tras la subida al poder del dictador Francisco Franco (1939-1975). Llegó a Santo Domingo en 1940 procedente de Burdeos y trabajó como violinista y redactor del diario La Nación. Luego se trasladó a Guatemala debido a su participación en La Poesía Sorprendida, revista perteneciente al grupo homónimo del que formó parte y que terminó siendo censurada durante el régimen de Rafael L. Trujillo. También por desacuerdos ideológicos, esta vez perseguido por estanilistas, reemigró en enero de 1950 a Puerto Rico y de allí pasó a residir en Estados Unidos por casi tres décadas, de 1957 a 1985 (Fernández Granell, 2000: 59-67). La obra Isla cofre mítico, publicada en 1951 durante el exilio de Granell en San Juan, se inscribe dentro de una red de discursos sobre la insularidad en el Caribe hispano de la que habían formado parte otros exiliados españoles, entre ellos Juan Ramón Jiménez y María Zambrano. ${ }^{3}$

${ }^{3}$ En mi libro El exilio español ante los programas de identidad cultural en el Caribe insular (1934-1956) me dediqué a estudiar la dimensión que aporta Isla cofre mítico a las teorías precedentes de otros españoles sobre la insularidad en el Caribe hispánico. Junto a otros exiliados, Jiménez y Zambrano participaron en los discursos sobre la insularidad hispanocaribeña promulgados por la Generación del Treinta en Puerto Rico -cuyo 
Al igual que este escritor exiliado en tierras americanas, las circunstancias políticas adversas llevaron a Carpentier a vivir fuera de su país, Cuba, por largos periodos de tiempo. Hijo de padre francés -Georges Carpentier- y madre rusa -Catherine Blagoobrasoff, aunque conocida en Cuba como Lina Valmont-, el escritor dominaba perfectamente el francés. De niño se comunicaba en este idioma con sus padres y realizó estudios en el Liceo de Jeanson de Sailly tras su llegada a Francia en 1912. La biografía temprana del autor, incluidos aquellos años en París hasta su regreso a La Habana en 1921, es un período poco documentado, confuso y de versiones variables. Se conoce, no obstante, la confluencia de idiomas del escritor. Junto al francés adquirido como primera lengua, también dominaba el español por influencia paterna y a través de su vida en Cuba. Pero en su español se advertía un acento afrancesado, con interferencias léxicas y una tendencia a arrastrar la "erre" propia de su idiolecto (González Echevarría, 2003: 69; Wahlström, 2018: 103-104). De sus años posteriores en Cuba, cabe destacar su activismo político como parte del Grupo Minorista y la Revista de Avance, que le ocasionaría el encarcelamiento tras firmar en 1927 una declaración en contra del dictador Gerardo Machado (Wahlström, 2018: 69). Una nueva etapa francesa, de 1928 a 1939, le permitió entrar en contacto con los máximos representantes de los movimientos de vanguardia gracias a su compañero Robert Desnos, quien le ayudaría a huir de la isla. Y si bien participó en la revista Révolution Surréaliste, fundada por André Breton, también se unió a sus detractores más tempranos. Participó así en el panfleto paródico "Un cadavre” en 1930, junto a otros miembros decepcionados con la intransigencia del fundador del surrealismo. ${ }^{4}$

Es en esta etapa de formación, según Alexis Márquez Rodríguez, cuando Carpentier "[...] vislumbra que el tema fundamental de su obra futura está en América. Un continente, mejor aún, una realidad que le pertenece, pero a la cual no conoce suficientemente" (1984: 20). Así, desde la distancia, en la Europa de entreguerras, el joven Carpentier se interesa por conocer y estudiar la América que apenas llegó a conocer de niño. Comienza entonces a rastrear desde Francia, según Márquez Rodríguez, aquel terreno prácticamente inexplorado, por medio de lecturas y discusiones con otros intelectuales latinoamericanos fuera de sus países: "[...] el venezolano Arturo Uslar Pietri y el guatemalteco Miguel Ángel Asturias, con quienes llega a tener una amistad entrañable y duradera" (Márquez Rodríguez, 1984: 20). Su preocupación por aprehender América, aquella búsqueda de lo auténtico y genuino, surge, por paradójico que resulte, en el ambiente cultural parisino de exploración de escenarios exóticos y a través del ejercicio de experimentación con las vanguardias europeas.

Los vínculos fuera de la isla de este escritor incipiente no solo se circunscriben al escenario francés. En España conoce a miembros de la Generación del 27 y, en plena guerra civil, en julio de 1937, participa en Valencia en el II Congreso para la Defensa de la Cultura. Y si bien regresa a la isla

mayor representante fue Antonio S. Pedreira con su ensayo Insularismo (1934) - y el Grupo Orígenes en Cuba, de cuya relación con el Nobel andaluz surgió el Coloquio con Juan Ramón Jiménez (1937) de José Lezama Lima. El libro de Jiménez Isla de la simpatía (1981) y el ensayo "La Cuba secreta" (1948) de Zambrano, así como otras reflexiones de la filósofa tras su paso por La Habana y San Juan, evidencian el diálogo entre intelectuales locales -en su mayoría descendientes de españoles, y exiliados de la España republicana, en la búsqueda de una expresión insular.

${ }^{4}$ Los colaboradores del panfleto fueron G. Ribemont-Dessaignes, Jacques Prévert y Raymond Queneau, así como Roger Vitrac, Michel Leiris, Georges Limbour, J.-A. Boiffard, Robert Desnos, Max Morise, George Bataille, Jacques Baron y Alejo Carpentier (Müller Bergh, 2006: 510). 
en 1939, huyendo de las guerras en Europa, vuelve a ausentarse entre 1945 y 1959, residiendo en Venezuela hasta la subida de Fidel Castro al poder. A lo largo de su vida, además, trabajó como consejero cultural en embajadas de Cuba en países iberoamericanos y en la Europa del Este y, en sus últimos años, a partir de 1966, ejerció como "ministro consejero" en la embajada de París (González Echevarría, 2019: 63). Esta reducida nota biográfica evidencia las idas y venidas de la isla emprendidas por Carpentier, así como el parentesco biológico, cultural e intelectual con Europa del creador de la tesis sobre lo real maravilloso.

En el ensayo "Lo real maravilloso de América" (1948), que prologaría su famosa novela El reino de este mundo (1949), Carpentier proponía presentar la "fantasía" americana de manera rutinaria, sin el efecto sensacionalista observable en la mirada del hombre occidental. ${ }^{5}$ Para plasmar esa sensibilidad era necesario, según el autor, describir toda aquella "maravilla" sin recurrir a la tradición europea. El interrogante de quién podría adjudicarse el legítimo papel de representante de América, nos hace cuestionar si realmente Carpentier, de origen europeo y formado intelectualmente en París, logró plasmar la autenticidad americana a la que aspiraba en su ensayo. Partiendo de esta duda, el presente estudio girará en torno a las siguientes preguntas: ¿en qué diferían el acercamiento insular de Granell y los argumentos de los que se sirvió Carpentier para representar el paisaje de América Latina?; ¿A qué modelos recurrieron ambos escritores y qué problemas presentaban estas dos representaciones del escenario americano? Y, finalmente, ¿se podría interpretar Isla cofre mítico como una respuesta o reacción a las críticas hacia la corriente surrealista que aparecen en el ensayo de Carpentier?

\section{Carpentier y el surrealismo en "lo real maravilloso"}

El ensayo o "manifiesto" de Carpentier (Müller Bergh, 2006: 491) es, pese a su brevedad, de gran aporte para entender sus esfuerzos por explorar en el terreno literario una sensibilidad latinoamericana, emancipada del canon occidental. El texto comienza ilustrando elementos de la literatura fantástica fallidos para aprehender la realidad de América y finaliza ofreciendo casos específicos de representación de una expresión autóctona. A juicio del autor, aquella magia cotidiana quedaba preferentemente localizada en el escenario haitiano, país al que viajó en 1943 y donde pudo visitar la fortaleza del emperador negro Henri Christophe (1767-1820), recreada en El reino de este mundo. Partiendo de un hecho real, la novela trata de la rebelión de los esclavos Mackandal y Bouckman, y de la subida al poder de Christophe, quien llegó a ser presidente (1807-1811) y rey (1811-1820) de la parte Norte del actual Haití. A partir de esta dimensión histórica de la novela, Carpentier aportaba un elemento nuevo -lo real- al concepto europeo de "lo maravilloso".

El inicio del ensayo apunta corrientes de la literatura europea cuyos recursos y técnicas de representación de lo fantástico nunca podrían aplicarse a la "maravillosa realidad" de América (Carpentier, 1973: 4). Ni las aventuras de la corte del Rey Arturo, ni los caballeros de la Mesa Redonda, ni el

\footnotetext{
5 "Lo real maravilloso de América" (a partir de ahora "Lo real maravilloso"), se publicó originalmente en El Nacional de Caracas el 18 de abril de 1948. El subtítulo del ensayo, "(Prólogo del libro inédito 'El reino de este mundo') por Alejo Carpentier", adelantaba la intención del autor de adherir desde un comienzo este texto introductorio (la teoría) al cuerpo de la novela (la práctica).
} 
mago Merlín y otros personajes sorprendentes que protagonizan acontecimientos inexplicables e irracionales de hechizos y brujerías, se asociaban de manera alguna a la fantasía americana. Tampoco las técnicas surrealistas, ni sus extrañas combinaciones -como el famoso "encuentro fortuito del paraguas y de la máquina de coser sobre una mesa de disección" (4) de Isidore Lucien Ducasse, Conde de Lautréamont- podían representar de manera alguna la complejidad de América Latina. La corriente surrealista aproximaba dos objetos completamente extraños, provocando un efecto lírico o artístico insólito, nunca antes apreciado. Pero aquellas formas y prácticas tan extravagantes como absurdas llegaron a convertirse, según Carpentier, en "fórmulas consabidas" de imaginación limitada (4). Los relojes amelcochados, los maniquíes de costurera, los monumentos fálicos, los paraguas, las langostas o las máquinas de coser (14), -y nótese aquí la referencia a Dalí, entre otros antecedentes surrealistas-, son para el autor meras expresiones manidas, artificiales, rígidas. La repetición mecánica de dichas fórmulas sin lograr el efecto sorpresivo inicial y rompiendo con la espontaneidad del arte, no respondían sino al acto mecánico de "aprenderse códigos de memoria" (4). Para Carpentier, lo que una vez fue insólito, lo que en algún momento causó extrañeza, se convertiría, tras el uso abusivo de sus formas, en un cliché fastidioso y monótono.

La cadena de intertextos que conforman el discurso tanto de "Lo real maravilloso" como de Isla cofre mítico muestra, por un lado, el nivel de erudición de sus respectivos autores y, por otro, el diálogo frecuente de ambos textos con intelectuales que podían identificar aquellas fuentes. En ambos casos, la mayor parte de estas referencias -explícitas o no- tenían una relación muy estrecha con la corriente surrealista. En el caso de Carpentier, por ejemplo, éste alude a Arthur Rimbaud, al Marqués de Sade, Alfred Jarry y Matthew Gregory Lewis, entre otros exponentes europeos de gran significación para la corriente surrealista. En otras ocasiones se trataba de alusiones a los representantes mismos de dicha corriente tanto en Europa -André Masson, Yves Tanguy, Max Ernst, Salvador Dalí, y por supuesto, el mismo Breton- como en América -Wifredo Lam y Jacques Roumain. ${ }^{6}$

Junto a las obras no aptas para retratar la maravillosa autenticidad americana -el "Burro devorado por un higo", del Conde de Lautréamont, los "Caballos devorando pájaros" de Masson, etc.-, Carpentier ofrece ejemplos específicos de quiénes, a su juicio, tienen el privilegio de representarla. Y de entre ellos destaca un "pintor de América" (Carpentier, 1973: 4), Wifredo Lam (1902-1982), artista cantonés-mulato oriundo de Cuba. En la cita siguiente, Carpentier apunta con el dedo a uno de los mayores agentes del surrealismo plástico, el mismo Masson, advirtiendo sus limitaciones artísticas en la representación del paisaje antillano:

Pero obsérvese que cuando André Masson quiso dibujar la selva de la isla de Martinica, con el increíble entrelazamiento de sus plantas y la obscena promiscuidad de ciertos frutos, la maravillosa verdad del asunto devoró al pintor, dejándolo poco menos que impotente frente al papel en blanco. Y tuvo que ser un pintor de América, el cubano Wifredo Lam, quien nos enseñara la magia de la vegetación tropical, la desenfrenada Creación de Formas de nuestra naturaleza -con todas nuestras metamorfosis y simbiosis-, en cuadros monumentales de una expresión única en la pintura contemporánea (Carpentier, 1973: 4).

\footnotetext{
${ }^{6}$ Merece la pena la lectura de Müller Bergh (2006), quien realiza un trabajo pormenorizado de identificación y explicación de fuentes y referencias en el texto de Carpentier.
} 
La supuesta incapacidad del pintor francés para plasmar en el lienzo el paisaje martiniqués no es del todo cierta. Del contacto de Masson con las Antillas -al huir de la invasión nazi a Francia, semanas antes de su partida hacia Nueva York (1941-1945) - surge Antille, obra pictórica dedicada a la isla francófona. Además, la obra Martinique charmeuse de serpents (1948), de Breton, con quien Masson compartió su experiencia en el exilio, se encontraba decorada con nueve imágenes de su amigo pintor. ${ }^{7}$ La jungla, por otro lado, fue concebida en Cuba dos años después de que Lam regresara de Francia tras la Segunda Guerra Mundial en el mismo transatlántico que Breton y Masson, una vez adoptadas técnicas y formas de los ismos europeos. Del estilo artístico de Masson, Carpentier denuncia las formas "increíbles" que delatan la exageración y distorsión de sus paisajes, así como la "obscena promiscuidad" que psicoanaliza el follaje del trópico. En contraste con esta sensibilidad europea, incompatible -según Carpentier- con la maravillosa verdad, se observa en la obra de Lam la verdadera representación de "nuestra naturaleza". En la persistencia de un "nosotros" - "nuestras metamorfosis y simbiosis" -, así como en la exclusividad de "una expresión única", este se incluye en el privilegio de representar lo autóctono de la tierra americana.

Aunque sin mención alguna a la obra Martinique, es posible que en el campo de las letras Carpentier estuviera subestimando la mencionada obra de Breton publicada al mismo tiempo de "Lo real maravilloso". Si Lam -y no Masson- podía plasmar en el lienzo la realidad antillana, Carpentier -y no Breton- era la autoridad en letras para la representación de América Latina. La siguiente cita así lo demuestra:

Pero es que muchos se olvidan, con disfrazarse de magos a poco costo, que lo maravilloso comienza a serlo de manera inequívoca cuando surge de una inesperada alteración de la realidad (el milagro), de una revelación privilegiada de la realidad, de una iluminación inhabitual o singularmente favorecedora de las inadvertidas riquezas de la realidad, de una ampliación de las escalas y categorías de la realidad, percibidas con particular intensidad en virtud de una exaltación del espíritu que lo conduce a un modo de "estado límite" (Carpentier, 1948: 15).

De nuevo, la referencia implícita a Breton y sus acólitos se asoma en el colectivo ("muchos") que anuncia el párrafo; y nótese el tono sarcástico dirigido a los poetas-brujos disfrazados "de magos a poco costo". El resto de la cita describe con elocuencia la tesis de lo "real maravilloso" en el contexto latinoamericano. El propósito de Carpentier no era ni imitar ni deformar la realidad maravillosa de este escenario, sino retratar dicha magia como un componente alterno de la naturaleza de América. De esta manera, el autor advertía la insuficiencia de los clichés occidentales en la representación de la magia tropical.

\footnotetext{
${ }^{7}$ Martinique charmeuse de serpents (a partir de ahora Martinique) representa la experiencia de Breton y otros artistas exiliados en la isla antillana tras abandonar Francia el 24 de marzo de 1941. Breton permaneció allí tres semanas, desde el 24 de abril hasta el 16 de mayo. Al comienzo de Isla cofre mítico, Granell alude así al periplo transatlántico: "En el mismo barco que transportó a Breton de Europa a América, en 1941, iban André Masson, Wilfredo Lam, Víctor Serge, Pierre Mabille; en fin, alemanes, austriacos, checos, españoles, franceses, belgas, cubanos. Del barco y de la isla a que arribó [...] trata este libro" (Granell, 1996: 13).
} 
Pero, además, "la sensación de lo maravilloso presupone una fe" (Carpentier, 1973: 5). Esta fe es el término más eficaz al que Carpentier acude para diferenciar lo "real maravilloso" de cualquier manifestación de lo fantástico en otras literaturas. Según él, la magia americana pasa inadvertida para quienes conviven con ella y creen en sus poderes. En cambio, "lo maravilloso invocado en el descreimiento -como lo hicieron los surrealistas durante tantos años- nunca fue sino una artimaña literaria, tan aburrida, al prolongarse, como cierta literatura onírica 'arreglada', ciertos elogios de la locura, de los que estamos muy de vuelta" (5). Ni la imaginería surrealista ni el realismo existencialista, por ejemplo, son géneros viables, según Carpentier, porque Europa no cree en el milagro, sino que acude a él para satisfacer sus carencias imaginativas. Los hechos extraordinarios que el autor narra en El reino de este mundo nunca hubieran podido ser aprehendidos con el arte europeo, pues se trata de una realidad incognoscible en el viejo continente: "[...] todo resulta maravilloso en una historia imposible de situar en Europa, y que es tan real, sin embargo, como cualquier suceso ejemplar de los consignados, para pedagógica edificación, en los manuales escolares" (6).

El desapego del autor hacia la corriente surrealista se produjo tempranamente, como evidencian la mencionada afrenta socarrona a Breton en "Un cadavre" y el texto "El escándalo de Maldoror", aparecido en la revista Carteles en abril de 1930 (Müller Bergh, 2006: 510-511). En este último rebasan el humor y la ironía para deshonrar una vez más al maestro surrealista. En el diálogo probablemente ficticio entre dos latinoamericanos residentes en París, el licenciado Martínez y un narrador, comentan el asalto nocturno producido por siete individuos vinculados a la corriente surrealista en un bar de alterne recién inaugurado, y cuyo nombre, Maldoror, había sido sugerido por uno de los doce firmantes de "Un cadavre", Roger Vitrac. El nombre del cabaret hacía eco de la obra del Conde de Lautréamont, Les chants de Maldoror, cuyo autor, como ya comentamos, constituía un referente fundamental para la vanguardia bretoniana. La indignación de los maestros -André Breton, Louis Aragon- provocó el altercado que el licenciado, testigo del asalto, estimaba de bochornoso: “¿Y esas cosas acontecen en una capital europea? ¿En los dancings de París? ¿Y nos quieren dar lecciones a nosotros los de América? (16)”. Detrás de aquella jocosa conversación se percibía un distanciamiento artístico, generacional y geográfico entre las "gentes civilizadas" responsables del alboroto y aquellos residentes latinoamericanos en la capital europea, que comentaban escandalizados el asalto.

Las ideas sobre lo real maravilloso comenzaron a forjarse a comienzos de los años treinta, así lo evidencian escritos como "América ante la joven literatura europea” (Müller Bergh, 2006: 494). En este ensayo, firmado desde París en mayo de 1931, se percibe el sentimiento antieuropeo del autor, así como el aplauso de la acertada opinión de los jóvenes artistas encuestados en su revista Imán, redactada en español y editada en París. Aquellos diez escritores de las "nuevas generaciones", y en actitud de rebeldía contra corrientes y maestros, quedaban exentos, según Carpentier, de la inexperiencia -si no incompetencia- del artista europeo ante los asuntos sobre América. Y no solo excusaba al grupo de dicha incapacidad, sino que le ofrecía voz y autoridad al cuestionar en dicho sondeo lo siguiente: “¿Cómo se imaginan ustedes a América Latina?”, “¿cuál habrá de ser su posición ante Europa?” y “¿cuáles son, a su juicio, sus problemas fundamentales?” (Carpentier, 1931: 30). 
A pesar del tono marcadamente martiano en cuanto al futuro del nuevo continente, "América ante la joven literatura europea" no dejaba de forjar una expresión del escenario latinoamericano fundamentada en las opiniones de los compañeros encuestados. G. Ribemont Dessaignes, Philippe Soupault, Nino Frank, Robert Desnos y Walter Mehring, entre otros participantes, defendían la emancipación americana de una Europa decadente, y advertían el advenimiento de un continente rico en expresión que llegaría a invadir "culturalmente a la vieja España” (51). Uno de los males, de las "debilidades" de los artistas actuales de América Latina era, concluía Carpentier, la imitación de las preceptivas europeas. Frente a la postura de seguimiento, sumisión y aceptación de una tradición heredada, el autor proponía "comenzar a ofrecer expresiones genuinamente representativas de la sensibilidad latinoamericana" (1931: 54). Y para ello Carpentier se enorgullecía de cultivar en su escritura y en su música estilos "nutridos de esencias criollas" (54). También anunciaría con interés la novela en la que estaba trabajando, ¡Écue-Yamba-Ó! (1933), de la cual se habían publicado algunos fragmentos en el primer número de Imán. ${ }^{8}$

Estos y otros argumentos afines reaparecen años después en "Lo real maravilloso". En su propuesta aparecen casos concretos de sensibilidad vs. artificiosidad en la representación de una expresión propiamente americana. Regresemos a la mirada nativa de Lam en La jungla (1943) y la foránea de Masson (1896-1987) en Antille (1943), cuadros coetáneos cuyos autores están muy presentes en el ensayo de Carpentier. Siguiendo su lógica para discernir entre lo auténtico y lo impuesto, Antille representaría para Carpentier la mirada extraña, sobrenatural, de las islas; destacando el componente exótico, extraordinario, del paisaje antillano. Lo mágico en La jungla, en cambio, quedaría incorporado como parte de la naturalidad de su tierra, de sus tradiciones, sin la extravagancia, a la que acude el europeo y con la fe de quien cree en el milagro. Los dos paisajes difieren sobremanera en sus tonos, formas y temas. Aun así, no resultan del todo observables la frivolidad surrealista en un cuadro foráneo como Antille y la autenticidad del paisaje local retratado en $L a$ jungla. Se trata de un ejercicio visual arduo para quien contempla ambos paisajes. No obstante, el cuadro de Masson invita en gran manera a participar del panorama sensual de las Antillas. Destaca en él una silueta desmembrada de piel cobriza, probablemente de mujer, con labios, hombros y senos voluptuosos. En sus contornos destaca una vegetación de tonos variados representativa de la frondosidad antillana. La imagen incita al disfrute de la sensualidad femenina y la exquisitez del paisaje. Son motivos temáticos que atienden al estereotipo occidental del goce sensorial del visitante en contacto con lo nativo y en particular con la mujer antillana.

A las curvaturas improvisadas que predominan en la obra de Masson se impone la verticalidad y la geometría del paisaje retratado en La jungla, así como la circularidad de algunas de sus formas. Destacan en esta los senos en forma de coco y la desnudez de los glúteos de las cuatro figuras

${ }^{8}$ Curiosamente, la correspondencia de Carpentier con su madre Lina evidencian que, pese a haber renegado de $; E ́ c u e-Y a m b a-O ́$ ! hasta el punto de evitar por muchos años su reedición, el autor se encontraba en un principio satisfecho con el resultado. Le cuenta a su madre que se trataba de un trabajo "paciente" y "acabado", y anticipa (o imagina) el éxito de la novela comparándolo con la obra gauchesca de Ricardo Güiraldes, Don Segundo Sombra (cit. en Wahlström 32). Guadalupe Silva ha estudiado esta etapa de expresión negrista en Carpentier. Según Silva, la reseña no del todo favorable de iÉcue-Yamba-Ó! realizada por su amigo Marinello en 1937 provocaría el descontento de Carpentier, pero también actuaría como catalizador para proyectar en su segunda novela, El reino de este mundo, un trabajo más maduro y en sintonía con la tesis que apuntaría en el prólogo, superando ya "un negrismo decorativo" (Silva 63). 
predominantes en el cuadro. Se trata de un paisaje mucho más complejo, más atractivo en los ojos de quien lo observa. Frente al personaje central femenino, único, retratado en Antille, priman en La jungla siluetas firmes rodeadas de máscaras y motivos afro-religiosos, muy al estilo del primitivismo que frecuenta la técnica cubista. La fauna abundante queda visualizada con los altos tallos de caña -imagen del sistema esclavista- y las hojas que adornan el cuadro. En todo ese ambiente selvático resulta insólita la aparición en la parte derecha superior de una mano menuda que sujeta una tijera de metal, imagen de posible evocación futurista. Se trata de una obra tremendamente trabajada, meticulosa y original, donde no existe espacio alguno para el descanso visual, donde la mirada fija en el cuadro no es suficiente para aprehender la maravilla que en él se contempla. Pero ante lo dicho, al igual que Antille, la sensualidad y el primitivismo son fácilmente apreciables y, de la misma manera, siguiendo la lógica de Carpentier, ambos reflejarían la influencia occidental en su interpretación de América.

Al margen del grado de autenticidad y de la calidad artística de Antille y La jungla, ambos cuadros, no solo el de Masson, representan la confluencia de expresiones artísticas predominantes en Europa. Aunque Lam comenzó su carrera como artista plástico en la Escuela Profesional de Pintura y Escultura San Alejandro, de La Habana, se ausentó de su isla natal durante varios años. En 1923 viajó a España para estudiar en la Academia de San Fernando de Madrid y, al igual que Carpentier, mostró una preocupación en la defensa de la Segunda República durante la Guerra Civil Española. En 1938 se trasladó a París, donde conoció al pintor sevillano Pablo Picasso, con quien entabló gran amistad y a través del cual tuvo acceso al mundo artístico parisino. Fue precisamente gracias a Picasso y Dora Maar que Lam conoció a Breton (Stokes Sims, 2002: 6) y, con él, a Benjamín Péret, Pierre Loeb y otros artistas franceses. ${ }^{9}$ Esto le ayudó a introducirse en los círculos más selectos de las vanguardias artísticas de la primera mitad del siglo XX. Fue además fuera de la isla, durante sus visitas al Museo del Hombre en compañía del etnólogo Michel Leiris, donde encontró referentes de primera mano del arte y la escultura africanos que tanto influirían en su obra. Ya años atrás, como observa Lowery Stokes Sims, se vislumbraba en el cuadro Sans titre (1937) la huella del continente africano que éste pudo apreciar en sus años de residencia en España (2002: 19-21).

Sin duda alguna y, al igual que su compañero Lam, el contacto de Carpentier con los ismos europeos así como con la atmósfera cultural e intelectual que por años pudo apreciar en la vieja Europa, dejaron huella en su obra creativa. Estos argumentos invitan a reflexionar sobre la consideración del mito autorial carpentiano como discurso legítimo sobre la realidad americana, y la descalificación de interpretaciones "foráneas", artificiales y postizas a juicio del autor. Nos encontramos ante un terreno resbaladizo y problemático, en donde entrarían en juego la posible inclusión o exclusión de voces sobre discursos interpretativos estimados como válidos o descartables según la geografía, origen y naturaleza de quien participa en ese debate identitario. Si así fuera, y siguiendo la lógica

\footnotetext{
${ }^{9}$ Además, la relación excepcional entre los Breton y Lam, y su compañera Helen Holzer, se deja ver no solo en París sino en América, al zarpar todos juntos desde Marsella en el "Capitaine Paul Lemerle" rumbo a Martinica: "Wifredo Lam had lately illustrated Breton's poem Fata Morgana. Breton was delighted to find the right titles for Lam's paintings. He also furthered Lam's career by recommending him to the Pierre Matisse Gallery in New York, where Lam made his American debut. But perhaps more telling of all was the poem that André Breton had written for Helena's birthday in Marseille in January 1941" (Russell: 1999, 16). En sus memorias tituladas Wifredo and Helena, la ex-esposa de Lam narra cómo Carpentier los visitaba con frecuencia, y cómo ambos coincidieron en los años veinte en Madrid y a comienzos de los cuarenta en París: "Our relationship with him [Carpentier] and his beautiful wife Lilian was close. We visited back and forth and went to many events together. In December 1942, during a visit, he happened to see La silla on an easel and liked it so much he bought in on the spot" (Benítez: 1999, 81).
} 
de Carpentier en su ensayo fundacional, habrían de ser considerados factores de tipo racial, genérico y sexual, entre otras muchas variantes, para el resultado de un acercamiento global e inclusivo, con los matices y tonalidades de América en su totalidad.

\section{La América surrealista de Granell en Isla cofre mítico ${ }^{10}$}

En la representación literaria de su encuentro con las islas, Granell, al igual que Masson y Lam, se sirvió del referente de la vanguardia y más en particular de la obra bretoniana Martinique, que el artista coruñés elogió en su libro dedicado a las islas. Una de las fotografías más divulgadas de Granell en el exilio puertorriqueño de los años cincuenta muestra al artista entregando a Juan Ramón Jiménez su Isla cofre mítico, libro dedicado al universo insular y en particular a las islas del exilio antillano que ambos españoles vivenciaron. ${ }^{11}$ En su valoración sobre el libro de Granell, dos años después de su publicación, el poeta onubense lo describía como "[...] un libro lleno de májica realidad imajinera" (Jiménez: 1953, 3). Reproduzco la reseña completa:

Isla es el título del atractivo libro de Eugenio Fernández Granell. En el pintor más o menos sobrerrealista que es Granell, hay un escritor nato. No sé por qué me imajino que Granell fue escritor antes que pintor. Y creo que su pintura se humanizaría más con la alternancia de su escritura impresionista. Porque si la imajinación no puede ser sino cosa del hombre, también lo humano es fatalmente cosa de la imajinación. Isla es un libro lleno de májica realidad imajinera. El estilo es vivo, limpio y fino. Escriba, Granell, escriba (Jiménez, 1953: 3).

En dicha reflexión, Jiménez identificaba dos elementos asociados a la creación artística de Granell: lo fantástico -el lado mágico de su imaginación- y lo real -lo humano, la realidad que abarca su escritura-; premisas ambas que remiten, sin ser mencionada, a la idea de lo "real maravilloso". Jiménez apremia el ejercicio literario del artista coruñés y lo valora positivamente sobreponiéndolo a sus cualidades artísticas como pintor y escultor. También le invita a que practique el ejercicio de la escritura, estimando la literatura de Granell como seductora, dinámica y elegante. ¿Qué atractivo podría tener aquel libro para el autor de Platero y yo, poeta sumamente crítico y pulcro en su obra, además de parco en elogios hacia otros jóvenes españoles? Pónganse como ejemplo las conocidas polémicas con los miembros de la Generación del 27. Sorprendentemente, Isla cofre mítico cayó en gracia en manos del maestro. Y es que el contenido, la organización y presentación del libro debieron ser de su agrado, no solo por el tema abordado -las islas caribeñas presentadas en toda su exoticidad, como un fenómeno por descubrir- sino por la seriedad en el trabajo de maquetación y edición, al cuidado de la Editorial Caribe.

Isla cofre mítico consta de una introducción y doce secciones breves encabezadas por siluetas abstractas del mismo autor trazadas en tinta negra. El color terroso de la cubierta nos transporta hacia un escenario colonial de paisajes rurales. En la mitad inferior de esta, Granell ilustra con pincel propio criaturas salvajes de plumajes azules y rosáceos que destacan sobre un fondo blanco.

\footnotetext{
${ }^{10}$ Las ideas de este apartado han sido recogidas de forma más detallada en mi libro El exilio español, cuyo tercer capítulo está dedicado a la figura de Granell en el Caribe y se recogen parcialmente aquí con autorización de la editorial Iberoamericana/Vervuert (Cañete Quesada, 2011: 180-212).

${ }^{11}$ La foto y reseña de Jiménez se reprodujeron en la segunda página de la edición primera de Isla cofre mítico. La imagen también aparece en Fernández Granell (2000: 62 y 1998: 9). Con Jiménez y Granell se encontraban también Jaime Benítez, rector de la Universidad de Puerto Rico y Sebastián González García, decano de Humanidades de esa misma universidad.
} 
El resto de la parte inferior quedaba reservado para el nombre del artista, abreviado con iniciales “e. f. granel" e impreso modestamente en letras oscuras. La misma disposición de tamaño y color se observa en el subtítulo de la obra: "cofre mítico", situado justo encima del dibujo. Más arriba y en un tamaño mucho mayor figura la palabra "ISLA", que junto al colorido plumaje de la imagen granelliana ocupa un lugar central en la cubierta. Sin lugar a dudas, tanto el formato como los tonos y las formas escogidos por el autor nos avanzan la línea temática del libro en sus doce secciones: 1) Crisol mágico, 2) Prestigio de las islas, 3) Carga magnética, 4) Triángulo isleño, 5) Pájaro sueño, 6) Pechos flotantes; 7) De norte a Eon, 8) Isla encantada, 9) Siglo de islas, 10) Bibliomancia, 11) Senos de fuego y 12) Cofre mítico.

Los títulos de cada sección apelan a todo un universo simbólico del que Granell se sirve para representar la maravilla de las islas. En su mayoría, estos títulos remiten a la geometría de los espacios insulares; a la supuesta magia, sensualidad y feminidad que, según él, exhuman estas porciones de tierra; y también al magnetismo irresistible para quienes las "descubren". A simple vista estos y otros motivos temáticos que se agolpan en el imaginario granelliano no aportan algo sustancialmente nuevo a la literatura más representativa del exilio español sobre el Caribe. De hecho, estos tópicos tan recurrentes para el visitante europeo formaban parte de un discurso colonialista prácticamente superado para el momento de la publicación de Isla cofre mítico. Ya en propuestas anteriores, más de diez años antes, hubo acercamientos similares de escritores que ensalzaron aquel tipo de vida alternativo en el refugio insular. Todos ellos, además, acudieron a una misma retórica basada en lo puro y virginal del ambiente, la sensación de refugio y recogimiento, el espacio natural libre de conflictos bélicos, el paraíso exento de sufrimiento, etc., que supuestamente significaron para aquel grupo de exiliados los universos insulares.

Pero es suficiente leer unas cuantas páginas para advertir que Granell no sigue el mismo rumbo de la mayoría de sus compatriotas españoles. Junto a ciertas preocupaciones sociales, la diferencia mayor en este caso tenía que ver con el procedimiento estético de depuración conseguido a partir de la fuerza imaginativa e irracional que irradia el arte surrealista. Partiendo de lo que otras figuras locales y extranjeras habían aportado a los discursos sobre la insularidad, el escritor coruñés adapta estas ideas a la tendencia artística en la que para entonces se inscribía toda su obra. Cumplida más de una década de la presencia española en las Antillas, aquella pléyade de artistas surrealistas era -para Granell- la autoridad del momento para legitimar el espacio del "otro". Lo primero que llama la atención en la lectura de Isla cofre mítico es la deuda artística de Granell con Breton, desde su mismo primer encuentro. Tras su paso por Martinica, el barco Presidente Trujillo que llevaría al vate francés a Nueva York hace escala en Santo Domingo permitiendo así el primer encuentro con el maestro (Hubert, 1999: XXII-XXIII).

En Isla cofre mítico afloran los recuerdos más gratos de este artista gallego, fruto de su contacto físico con el trópico y de su compromiso con el arte surrealista, del que se sirvió para recrear sus recuerdos insulares. El saldo de Granell con el padre del surrealismo viene expresado en el epígrafe inicial del libro, dedicado "A Elisa y André Breton, en recuerdo de haberlos conocido en 
una isla" (Fernández Granell: 1996: 9). Aquel reencuentro se produciría de regreso a su país natal, en febrero de 1946, y en compañía de su tercera esposa, Elisa Claro, de origen chileno. Pero ya en la primera visita del poeta francés a Santo Domingo, el exiliado corunés sirvió como anfitrión de éste, Jacqueline Lamba -su segunda esposa-, su hija Aube y otros intelectuales que estuvieron junto con Breton en Santo Domingo: “[...] el doctor Pierre Maville [sic], autor de libros sobre lo maravilloso en la literatura; el pintor cubano Wifredo Lam, el escritor y revolucionario ruso Víctor Serge y su hijo Vlady, y la novelista alemana Ana Seghers" (Fernández Granell, 1986: 12). Paradójicamente, este tropiezo casual con el surrealismo tras su llegada a América cobró mayor fuerza para Granell fuera del ambiente parisino debido sin duda a su encuentro con otros europeos en circunstancias similares, con quienes llegó a compartir gustos y tendencias de similar naturaleza.

La obra Martinique es clave para entender la relación Granell-Carpentier, en tanto que en ella encontramos el eslabón entre los denuestos del cubano a la escuela surrealista y los elogios del coruñés a la obra bretoniana. Es precisamente ese distanciamiento o inclinación hacia Bretón y su corriente lo que mantiene a estos dos escritores -Granell y Carpentier- en constante diálogo, sin existir reciprocidad aparente en la obra de ambos. ¿Es Martinique, como Carpentier insinuaba, una falsa representación de las Antillas? ¿En qué consistía y qué relación existía entre la obra bretoniana dedicada a la isla francófona y la obra granelliana dedicada al espacio insular hispano en el exilio?

Como la obra de Granell, las páginas de Martinique se encuentran ilustradas con litografías en blanco y negro, en este caso, como ya he apuntado, de la mano de Masson. Tras una breve introducción aparece un escrito del mismo Masson titulado "Antille" (Breton, 1948: 13-14) en el que se aprecia la sensualidad del follaje selvático. En la segunda parte, titulada "Le dialogue créole entre André Breton et André Masson” (15-34), Breton disfruta del paisaje martiniqueño con su amigo pintor, mientras entablan una conversación filosófica sobre diversos artistas y escritores de paraísos insulares. Al diálogo le sigue "Des "épingles tremblantes" (35-46), en cuyas nueve notas se alternan descripciones maravillosas con alusiones al pasado colonial de la isla; entre ellas la plantación "La Pagerie" y Joséphine de Beauharnais (37), y la emancipación y abolición de la esclavitud en Martinica (39). La parte más extensa, "Eaux troubles" (47-82), ofrece un testimonio de los sucesos ocurridos a Breton después de su partida rumbo a Fort-de-France. El libro continúa con un texto dedicado a Aimé Césaire, "Un grand poète noir" (85-107), en el que incorpora una reseña detallada de su libro Cahier d'un retour au pays natal (1939) y concluye con un poema titulado “Anciennement Rue de la Liberté" (109-112) dedicado a una de las avenidas más concurridas de Fort-de-France.

En realidad, la obra de Breton no debió ser una novedad para Granell en el año de su publicación, ya que casi todos los escritos allí compilados habían salido a la luz poco después de que éste abandonara 
las Antillas. ${ }^{12}$ Aun así, no cabe duda de que aquel libro dedicado a una isla del trópico y cargado de imágenes inusitadas sobre su belleza vegetal, llevó a Granell a plasmar el exilio insular que él conoció, usando como referente el periplo bretoniano surrealista. Así, dos años más tarde, Isla cofre mítico rendía homenaje a esta obra transitoria -"en medio de la ruta"- cuyo tratamiento de la realidad antillana -según Granell- logró revitalizar el antiguo mito “casi esfumado" (Fernández Granell, 1996: 11). En los ojos del español, Breton es poco menos que el continuador del primer expedicionario europeo en las Antillas y la autoridad para representar la alteridad antillana en aquellos tiempos. Como tal, su libro Martinique habría de leerse como una readaptación del diario colombino de la mano de este otro "descubridor" de las Indias occidentales: "El colibrí seductor de tanto viajero americano abre con patético aleteo este cuaderno de bitácora que será tan importante como los diarios de a bordo de Colón” (Fernández Granell, 1996: 31).

Estas dos figuras emblemáticas -Colón y Breton-, que en opinión de Granell dejaron una huella indeleble en La Española, son la fuerza medular en la que se sostiene el discurso insular de Isla cofre mítico. Ya desde la primera parte titulada "Crisol mágico", Granell asocia la llegada de los primeros expedicionarios al llamado Nuevo Mundo con otra travesía transatlántica para él equiparables: la de quienes como los mencionados Breton, Masson, Lam, Serge y Mabille fueron arrastrados por navíos franceses hacia las costas de América. Dicha sección rinde homenaje a estos y otros artistas que hubieron de desplazarse a los archipiélagos caribeños. Más en particular, "Crisol mágico" rendía tributo al libro en el cual Breton detalla los pormenores de su travesía transatlántica hacia la isla de Martinica: "Del barco y de la isla a que arribó, de lo que quedaba en la estela del navío y de lo que se inauguraba ante su proa- "[... ' los gemelos sobre la costa norte de la isla cubren al instante la distancia que separa la percepción común del sueño de los poetas'-trata este libro" (13). Esta cita de Granell, con el intertexto de Breton, constituye una pequeña muestra de la importancia de Martinique en la configuración del discurso granelliano sobre las islas. La imagen del barco en movimiento escenifica el estado de transición que provoca el desplazamiento geográfico. Este cambio lleva a Granell a reconsiderar su identidad en el exilio a partir de un proceso sustitutorio de lo propio que va quedando atrás -“la estela"- por formas desconocidas -"su proa"- que suponen para éste el comienzo de una nueva etapa. A la imagen granelliana, Breton le añade la dimensión onírica del artista-viajero que logra con este desplazamiento visualizar su propio sueño de poeta.

Con tales ejemplos, no cabe duda de que Granell se sirvió del referente francés para plasmar en su propia lengua una experiencia surrealista similar en su encuentro maravilloso con las islas. De hecho, son tantas las referencias y los intertextos de esta obra de Breton en Isla cofre mítico- por no mencionar las coincidencias en el formato y la disposición de sus partes- que se podría argüir que este libro de Granell es una traducción fidedigna del anterior adaptado a un lector hispanohablante.

12 "Le dialogue créole" había salido publicado en enero de 1942 en Lettres Françaises (Buenos Aires) y "Eaux troubles" apareció en dos partes en el periódico Pour La Victoire los días 7 y 14 de febrero. En 1944 aparecería "Un grand poète noir" en las revistas Hémisphères y Tropiques; y en el mismo número de Hémisphères aparecen el poema "Antille" de Masson y "Des "épingles tremblantes", incluyendo como parte de este último "Anciennement Rue de la Liberté". 
El papel central que allí ocupan tanto Breton como la figura de Colón, nos deja entrever lo difícil que resultó para este exiliado resarcirse de los códigos occidentales para el (re)conocimiento de estos pueblos y culturas de América. Es más, existe en Granell un propósito difusor de estos moldes occidentales para el uso y disfrute del lector europeo. Si nos fijamos, este reprodujo partes del cuaderno de viajes de Breton de la misma manera que en su tiempo Bartolomé de Las Casas transcribió y difundió los diarios de Colón.

El ejercicio granelliano de traducción y reproducción de múltiples fragmentos de Martinique en su obra Isla cofre mítico muestra la sujeción artística de este autor a textos y fuentes que plasmaban una nueva realidad acorde a las necesidades de Occidente. Pero además, el poder de la traducción facilitaba la difusión de un libro surrealista como Martinique fuera del entorno cultural francófono. El éxito de la obra de Granell dependía a su vez de la revitalización del surrealismo en los países americanos donde fueron a parar miembros destacados de aquella corriente. La deuda estética, tanto en Martinique como en Isla cofre mítico, facilitó sin duda los lazos de unión entre aquellos dos vates del surrealismo que dilataron sus posibilidades creativas en el archipiélago caribeño.

\section{La mirada de América en Granell y Carpentier: reflexiones}

En el contexto de los discursos nacionalistas caribeños, en conflicto con una visión europea, he tratado de reflexionar sobre la idea en pugna de cuáles individuos podrían representar una identidad, a quiénes se les asigna la idea de hablar por la nación y qué discursos podrían resultar válidos o autorizados en el rastreo de identidades. Delinear quién tiene derecho o no a representar a un país, nación o comunidad, dependiendo del origen y la naturaleza del discurso, así como de quién lo presenta, es un asunto complicado. En primer lugar, porque la representación del Caribe, en el caso de Granell y Carpentier, por ejemplo, responde a fines muy dispares. La diferencia entre un libro surrealista como el de Granell y una novela como El reino de este mundo es que en esta última la maravilla de América pretende ser presentada en toda su cotidianeidad, mientras que el exiliado la utiliza a modo de estímulo, como fuente de inspiración para su creación artística. Carpentier no aplica esa magia a sus demandas como escritor, sino que intenta representarlas de forma real. No se trata de un hecho extraño, sino un fenómeno cultural ordinario, libre del efecto estético y sensacionalista que le confiere el surrealismo. Destaca en cambio en Isla cofre mítico la combinación de moldes occidentales, y en particular la estética surrealista revitalizada a través de su encuentro con el escenario insular, en el contexto específico de las Antillas.

Los mitos clásicos a los que acude Granell son un material que Carpentier convierte nada menos que en carne de cañón en su escritura. Si Granell parece seguir unos parámetros historiográficos, Carpentier se encarga de desacralizar la historia, reescribiéndola y recreándola. Ante la idealización en Isla cofre mítico de figuras históricas como Colón, Carpentier desmitificaba la versión oficial granelliana, presentando en su novela El arpa y la sombra (1979) a un Almirante revolviéndose en la tumba y reconociendo el fraude de la conquista. ${ }^{13}$ Nótese, además, cómo las figuras de la familia

\footnotetext{
${ }^{13}$ Carpentier reaccionó fuertemente a la idealización y el estereotipo del escenario americano. El autor reconoce la limitación lingüística de los primeros expedicionarios para nombrar la realidad "oriental". Al traducir lo que ve, Colón distorsiona y empobrece la realidad americana: "En cuanto al paisaje no he de romperme la cabeza: digo que las montañitas azules que se divisan a lo lejos son como las de Sicilia, aunque en nada se parecen a las de Sicilia. Digo que la hierba es tan grande como la de Andalucía en abril y mayo, aunque nada se parece, aquí, a nada andaluz [...]" (Carpentier, 2002: 130). Ejemplos como éste muestran la pretendida desmitificación en esta novela de Carpentier de los discursos hegemónicos sobre la conquista.
} 
Bonaparte son retratadas en Isla cofre mítico con respeto y admiración, en particular el emperador y su esposa Josefina, de origen martiniqués: "En lo primero que se piensa al deletrear Mar-ti-ni-ca es en Josefina. Esta idea conduce a la de Napoleón, pero ya en la idea de Napoleón está la idea de la isla. Nacido en una isla, la isla preside su destino" (Fernández Granell, 1996: 24). La prudencia de Granell al retratar el cuerpo desnudo de la discreta Josefina en "Pechos flotantes", por ejemplo, para nada correspondía al cuadro lujurioso de sexualidad con el que se introduce a Paulina, hermana del emperador, en El reino de este mundo: "Como en la estatua de Josefina, los pechos se recatan, aún si pugnan por salir, bajo el pliegue ondulado del vestido de algas" (Fernández Granell, 1996: 36). El exotismo europeo quedaba exento en la mirada de Carpentier ante aquella "buena catadora de varones" (Carpentier: 1973, 27), que con su desnudez despertaba pasiones hasta en el más recatado de los esclavos y sirvientes en las Antillas francesas. Granell utiliza como precedentes de su discurso europeizante personajes históricos sacralizados de Occidente. Carpentier juega con ellos, los parodia sin reparos haciéndolos más verosímiles, más auténticos.

Ya he señalado cómo, consciente quizás de los detractores del surrealismo en el exilio americano, Granell utilizó la maravilla del trópico como un ejercicio de renovación estética, mientras que Carpentier no pasaba por alto las formas manidas a las que acudía esta corriente. Ahora bien, el problema mayor que presenta la tesis de Carpentier es que el término en sí, - "realismo mágico"- del que deriva "lo real maravilloso", tiene sus orígenes en el posexpresionismo alemán. Al parecer no hay duda de que fue el crítico de arte alemán Franz Roh el que acuñó la frase "realismo mágico" en su libro Nach Expressionismus (Magischer Realismus) (1925), publicado en Leipzig por Klinkhardt \& Biermann. Márquez Rodríguez explica cómo la popularidad del término en el mundo hispánico llegó a través de la editorial de la Revista de Occidente, dirigida por José Ortega y Gasset, en cuya versión traducida al español el subtítulo quedaba colocado al frente, haciéndolo más visible: "Realismo mágico. Postexpresionismo" (Márquez Rodríguez, 1984: 37). Guillermo Cabrera Infante así lo señala: “Tontos y pícaros coinciden siempre en la desinformación. Así se repite ahora en todas partes que Carpentier 'creó el realismo mágico'. No saben (o se olvidan) que esta etiqueta fue fabricada por un alemán llamado Franz Roh en 1924, cuando Carpentier acababa de salir del bachillerato en La Habana o de un lycée francés [...]" (Cabrera Infante, 1992: 374).

Además de la traducción de la obra de Roh, Carpentier debió tener conocimiento de las primeras aplicaciones al español de "realismo mágico" a través de los venezolanos Arturo Uslar Pietri y Vicente Gernasi. Esto explica que fuera tras su llegada a Caracas en 1945 cuando publicó su ensayo en el diario caraqueño El Nacional (Márquez Rodríguez, 1984: 78). También es importante recordar una vez más que la fecha coincide con la publicación de Martinique. Dados los contactos previos de Carpentier con el grupo surrealista en Francia, así como las referencias casi directas en Isla cofre mítico al prólogo, no es de descartar que uno de los propósitos del libro de Granell fuera respaldar la figura de Breton de las agresiones verbales contra el surrealismo del autor de "Lo real maravilloso". 
He señalado también cómo, para plasmar la sensibilidad de América era necesario, según Carpentier, independizarse del canon occidental y en la medida de lo posible, describir la maravilla del trópico sin la necesidad de recurrir a elementos foráneos. Pero en su intento de distanciarse de lo europeo nos encontramos con otro problema, ya que la nacionalidad cubana de Carpentier ha quedado en duda desde el descubrimiento de su origen suizo, once años después de la muerte del escritor. ${ }^{14} \mathrm{La}$ existencia de su partida de nacimiento en 1904, localizada en Lausana, y revelada públicamente por Gastón Baquero y Guillermo Cabrera Infante, fue solicitada por una de las esposas de Carpentier, Eva Fréjaville, con quien regresó de París en 1939 (González Echevarría: 2019: 62). Es más, es posible que los padres de Carpentier no llegaran a Cuba sino hasta 1914, es decir, cuando él contaba con 10 años de edad, hecho que explicaría, según González Echevarría, su ya mencionado acento francés al emplear el español (63). ${ }^{15}$ ¿Cuándo comenzó este escritor a reclamar su identidad cubana públicamente? Parece ser que ya para 1927, y por una cuestión política, Carpentier -que por entonces ocupaba el puesto de jefe de redacción de la revista Carteles- tras ser procesado y detenido, se proclamó como cubano. Y es que, según Sergio Chaple, “[...] a la salida de la cárcel se hallaban agentes de la policía judicial que procedieron a la detención de los extranjeros, los cuales fueron remitidos al buque de guerra 'Máximo Gómez' para su expulsión del país" (cit. en Wahlström, 2018: 134). Esta fecha marca el reclamo por parte del autor de su origen antillano, proclamándose como tal de forma perpetua hasta su muerte.

Entre las variadas razones apuntadas por la crítica -el repudio a la extranjería de sus padres, por ejemplo-, la insistencia en proclamar su identidad cubana en entrevistas y escritos desde su regreso de Europa pudiera tener que ver con ese deseo de adjudicarse el papel de representante de América. Otros críticos llegan incluso más lejos en su interpretación. Entre ellos, Michael Richardson cuestiona si realmente este escritor afrancesado y de origen criollo logró plasmar la autenticidad a la que el prólogo aspira. Richardson, además, reprocha la mirada resentida y poco generosa de Carpentier hacia sus cofrades franceses:

The Cuban writer Alejo Carpentier, while admitting his debt to surrealism, considered that it lacked authenticity in Europe: the European surrealist was condemned to a paucity of vision because surrealism was not embedded in society, the European cultural soil being too barren to sustain its richness. Its real domain was Latin America and the Caribbean, where magic remains part of everyday life. Surrealism thus becomes the appropriate means of expression in Latin America, but it is that surrealism divorced from its critical roots and recuperated as a "real marvellous," or the "magic realism" that today substantially conditions our idea of an appropriate Latin American literature. But this magic realism is, like negritude, a reification of reality in a particular (exotic) form appropriate to the Other which, although implying a separation from the traditions of Europe, is none the less defined in relation to those rejected traditions (Richardson, 1996,: 12).

\footnotetext{
${ }^{14}$ González Echevarría estudia los pormenores del asunto en el prólogo de la edición en español de Alejo Carpentier: el peregrino en su patria. (2003: 9-41)

15 “Como vimos, Carpentier señala que sus padres se fugaron a Bruselas en 1902 donde se casaron antes de viajar a Cuba el mismo año, dando la impresión de que simplemente pasaron por la ciudad. Sin embargo, en los catálogos llamados almanachs que conserva la ciudad de Bruselas en su página web oficial, hemos descubierto que un Georges Carpentier, estaba registrado como habitante de la ciudad desde 1905 hasta 1914 , con un hiato curioso en 1907. Dado que está registrado como 'architect-géomètre expert', podemos suponer que se trata del padre de Alejo. El primer año vivió en Rue de Noyer 57, el segundo en Rue de Praetere 16, y entre 1908 y 1914 en Rue du Vivier 91”. (Wahlström, 2018: 81)
} 
Richardson establece una diferencia fundamental entre la magia surrealista "sorpresiva" y la magia de América que se presenta como parte de la realidad cotidiana - "part of everyday life". Sin embargo, el crítico opina que, pese a los esfuerzos por deslindarse de las corrientes europeas, la mirada de Carpentier no logra representar una América real. Es más, Richardson llega incluso a relacionar el fenómeno de "lo real maravilloso" con las tendencias negristas anteriores falsificadoras de la realidad africana. Pero a pesar de estas deficiencias que apunta Richardson, cuya mayor crítica parece tener que ver con el fenómeno del boom y no tanto con este texto en particular, la teoría de Carpentier en los albores de los años cincuenta, ya cercanos al esplendor literario latinoamericano, suponían un paso más hacia el rastreo de una identidad americana sin atavismos ni precedentes.

Las diferencias que he venido apuntando sobre las técnicas surrealistas en la representación de América frente a "lo real maravilloso" son una llamada de atención al uso de motivos foráneos en la captación de lo autóctono. Ni tan siquiera corrientes iconoclastas como el surrealismo servían como mecanismos legítimos cuando se trataba de describir el Nuevo Mundo, según Carpentier. Mientras los surrealistas se empeñaban en retratar la originalidad paisajística antillana reciclando antiguos clichés reducidos a larvas, relojes y formas fálicas, Carpentier se esforzaba por ofrecer una mirada espontánea a la naturaleza del trópico. Sus historias pretenden romper con esta tendencia, retratando lo fantástico-americano como un hábito cotidiano. Granell proyecta de forma servil la imaginería de Europa sobre las Antillas. Carpentier la parodia y deshace.

Ahora bien, regresando a la problemática inicial que se ha venido planteando ante el contraste entre dos textos representativos de la realidad de América y, al margen del origen del autor, la inclusión de expresiones artísticas o el propósito de ambos discursos, ¿significaría entonces que en los discursos sobre identidad y nación, determinadas aportaciones gozan de autoridad y prestigio, mientras que otros razonamientos resultan impopulares, si no descalificados o despreciados, y por tanto descartables por ser abordados con un enfoque foráneo, con la mirada del visitante y el distanciamiento de quien contempla dicha realidad "desde afuera"? Y si tal es el caso, ¿quién determinaría los límites de lo aceptable o lo inaceptable en los asuntos sobre la nación y que criterios resultarían aplicables para validar o no una opinión, discurso o interpretación sobre el amplio paisaje latinoamericano, con todos sus ribetes, contornos y tonalidades, hasta el momento inapreciables en un único texto? Valgan como ejemplo lo discutido sobre Carpentier y Granell para, si bien no ofrecer una respuesta o solución al problema, abrir nuevos planteamientos y propuestas a los debates sobre identidad y nación en América Latina.

\section{BIBLIOGRAFÍA}

Benítez, H. (1999). Wifredo and Helena: My Life with Wifredo Lam, 1939-1950. Lausanne: Acatos Publisher.

Breton, A. (1942). Eaux troubles. Pour la Victoire, New York, (7), 5.

Breton, A. (1943-1944). Des “épingles tremblantes”. Hémisphères, 2(3), 16-20. 
Breton, A. (1944). Un grand poète noir". Hémisphères, 2(3), 5-11.

Breton, A. (1944). Un grand poète noir. Tropiques, (11), 119-126.

Breton, A. (1948). Martinique charmeuse de serpents. Paris : Sagittaire.

Breton, A. (2008). Martinique Snake Charmer. Trad. David W. Seaman. Austin: University of Texas Press.

Breton, A. y A. Masson (1942). Le dialogue créole. Lettres Françaises, (3), 1-7.

Cabrera Infante, G. (1992). Carpentier, cubano a la cañona. En Mea Cuba (pp. 370-388). España: Plaza \& Janés.

Cañete Quesada, C. (2011). El exilio español ante los programas de identidad cultural en el Caribe insular (1934-1956). Frankfurt/Madrid: Vervuert/Iberoamericana.

Carpentier, A. (1931). América ante la joven literatura europea. Carteles, 28 de junio, 30, 51 y 54.

Carpentier, A. (1930). El escándalo de Maldoror. Carteles, 20 abril, 16, 73-74.

Carpentier, A. (1948). Lo real maravilloso de América (Prólogo del libro inédito El reino de este mundo) por Alejo Carpentier. El Nacional (Caracas), 18 de abril, 8.

Carpentier, A. (1973). Prólogo. En El reino de este mundo (relato) (pp. 4-6). 6 ed. México: Compañía General de Ediciones.

Carpentier, A. (2002). El arpa y la sombra. 19 ed. México: Siglo XXI Editores.

Fernández Granell, E. (1986). Encuentro con E. F. Granell, por Antonio Núñez. Ínsula: Revista de Letras y Ciencias Humanas, (484), 1, 12.

Fernández Granell, E. (1996). Isla cofre mítico [Puerto Rico: Caribe, 1951]. Ed. facsimilar. Huelva: Fundación Juan Ramón Jiménez.

Fernández Granell, E. (1998). Granell en Puerto Rico (1950-1957). Coord. Natalia Fernández Segarra. Santiago de Compostela: Fundación Eugenio Granell.

Fernández Granell, E. (2000). Eugenio Granell. Ed. Laura García Lorca. Granada: Casa-Museo Federico García Lorca. 
González Echevarría, R. (2003). Alejo Carpentier: el peregrino en su patria. Madrid: Gredos.

González Echevarría, R. (2019). Los secretos de Alejo Carpentier. Nexos, 1 de enero, 62-64. Disponible en https://www.nexos.com.mx/?p=40633

Hubert, É.-A. (1999). Chronologie. En André Breton. Euvres complètes (XXI-XLVII). Paris: Gallimard.

Jiménez, J. R. (1953). Notas jenerales. Universidad, (65), 3.

Márquez Rodríguez, A. (1984). Lo barroco y lo real-maravilloso en la obra de Alejo Carpentier. 2 ed. México: Siglo Veintiuno.

Masson, A. (1943-1944). Antille. Hémisphères, 2(3), 21.

Müller Bergh, K. (2006). El prólogo a El reino de este mundo, de Alejo Carpentier (1904-1980). Apuntes para un centenario. Nueva Revista de Filología Hispánica (NRFH), 54(2), 489522. Disponible en http://www.jstor.org/stable/40300650

Richardson, M. (1996). Refusal of the Shadow: Surrealism and the Caribbean. Trad. Michael Richardson y Krzysztof Fijałkowski. London: Verso.

Russell, J. (1999). A Few Words from John Russell. En Wifredo and Helena: My Life with Wifredo Lam, 1939-1950 (pp. 13-17). Lausanne: Acatos Publisher.

Silva, G. (2015). Alejo Carpentier, del negrismo a lo real maravilloso. Anclajes, 19(1), 53-70. Disponible en https://cerac.unlpam.edu.ar/index.php/anclajes/article/view/946/945

Stokes Sims, L. (2002). Wifredo Lam and the International Avant-Garde, 1923-1982. Austin: University of Texas Press.

Wahlström, V. (2018). Los enigmas de Alejo Carpentier: La presencia oculta de un trauma familiar. Lund: MediaTryck Lund. 